\title{
Transparência do Banco Central e Mercado Financeiro: Evidências para o Caso Brasileiro
}

Helder Ferreira de Mendonça*

José Simão Filho**

\section{Resumo}

O principal objetivo deste artigo é uma análise empírica dos efeitos da transparência do Banco Central do Brasil sobre o mercado financeiro brasileiro. Além disso, é apresentada uma pequena revisão da literatura sobre a transparência do banco central. São examinados os impactos das diferentes dimensões da transparência da autoridade monetária na curva de juros. Ademais, os efeitos oriundos de variações no risco país são considerados neste estudo. Os resultados mostram que a transparência do Banco Central do Brasil serve como um guia para o mercado de juros futuros e que as diferentes dimensões da transparência contribuem para uma maior eficiência do mercado.

Palavras-chave: transparência; accountability; metas para inflação; curva de juros.

Códigos JEL: E52, E58.

\section{Abstract}

The main objective of this paper is an empirical analysis concerning the effects caused by Central Bank of Brazil transparency on the Brazilian financial market. Furthermore, a brief review of the literature regarding central bank transparency is presented. The effects of the different dimensions of the monetary authority's transparency on yield interest are examined. Moreover, the consequences regarding changes in the country risk are considered in this study. The findings denote that the Central Bank of Brazil transparency works as a guide for the future interest rate market and that the different dimensions of transparency contribute to a better market efficiency.

Keywords: transparency; accountability; inflation targeting; yield interest.

Submetido em agosto de 2009. Aceito em novembro de 2010. O artigo foi avaliado segundo o processo de duplo anonimato além de ser avaliado pelo editor. Editor responsável: Benjamin Tabak.

*Universidade Federal Fluminense, Niterói, RJ, Brasil. E-mail: helderfm@ hotmail.com

***Faculdade de Economia, Universidade Federal de Juiz de Fora, Juiz de Fora, MG, Brasil.

E-mail: jsimaof@oi.com.br 


\section{Introdução}

Os novos modelos de pré-comprometimento, utilizados pelos gestores da política monetária, se desenvolveram, em paralelo, à evolução das formas de comunicação do banco central (BC). A adoção de âncoras nominais nos anos 1990 mostra a importância da comunicação do $\mathrm{BC}$ na condução das expectativas de inflação dos agentes econômicos. A partir de então, o regime de metas explícitas (inflação, agregados monetários e câmbio) tem sido utilizado por muitos países industrializados e em desenvolvimento.

Com o passar do tempo, a prática dos BCs mostrou que os modelos de regras estritas eram falhos e que as incertezas do mundo real exigiam a utilização de modelos híbridos. Estes modelos combinam regras com discrição e criam soluções para alguns dilemas vividos pelas autoridades monetárias. Por exemplo, como reagir aos choques de oferta, ao desvio da meta de inflação e como explicar políticas restritivas em períodos de baixa inflação (sem que haja perda de credibilidade do BC). Neste contexto, a transparência do BC torna-se uma importante ferramenta de ligação entre as ações de curto prazo do $\mathrm{BC}$ e seus objetivos de longo prazo. São exemplos dessa conduta, a utilização de regras de previsão (forecast), as explicações relativas à duration da taxa de juros e a publicação de metas de inflação de longo prazo.

A necessidade de a autoridade monetária publicar suas previsões sobre a economia e, desta forma, criar uma nova (adicional) âncora nominal, tem sido debatido em diversos BCs. Muller \& Zelmer (1999) estudaram o efeito da publicação do BC sobre previsões de choques de oferta no mercado financeiro canadense. No que diz respeito à redução das incertezas para os investidores, os resultados obtidos reforçam a importância destas publicações. A justificativa é que as expectativas são formadas a partir de um conjunto de informações mais amplo.

Além do argumento acima, é esperado que a transparência econômica do BC ajude os agentes econômicos a anteciparem as ações de política monetária e que, por conseguinte, evite possíveis perdas de capital. A idéia é que a transparência reduz a incerteza por meio de aumento do conjunto de informações dos agentes econômicos promovendo uma menor assimetria de informações. Destarte, a transparência do $\mathrm{BC}$ tem um papel relevante na redução do prêmio de risco dos ativos e no aumento da eficiência do mercado financeiro.

O principal objetivo deste artigo é uma análise empírica dos efeitos da transparência do Banco Central do Brasil sobre o mercado financeiro brasileiro. Além desta introdução, o artigo encontra-se estruturado em mais duas seções. Na seção 2 faz-se uma apresentação sobre os referenciais teóricos e empíricos relativos à transparência do BC. Na seção 3 faz-se um estudo empírico sobre o impacto das diferentes dimensões da transparência do Banco Central do Brasil (BCB) nos juros futuros e, por sua vez, na curva de juros da economia brasileira. Por fim, é apresentada a conclusão. 


\section{Revisão da Literatura}

Alguns autores como Siklos (2000), Muller \& Zelmer (1999), Chada \& Nolan (2001), Geraats (2002), Chortareas et al. (2002), e Gürkaynak et al. (2005) estudam, de forma empírica, os efeitos da transparência do BC nas variáveis macroeconômicas e destacam os benefícios desta transparência para a economia.

Siklos (2000) mostra que períodos de maior transparência estão relacionados com períodos de curtose mais elevada e, portanto, com maior conteúdo informacional. Muller \& Zelmer (1999) enfatizam que o spread da taxa de juros (na economia canadense) reage, de forma significativa, às decisões de política monetária anunciadas pelo BC canadense. Conforme destacado por Clare \& Courtenay (2001) os mercados financeiros ficaram mais eficientes depois da introdução da independência operacional do BC do Reino Unido. Neste caso, os agentes econômicos reagiram, de forma mais intensa, nos cinco primeiros minutos depois do anúncio da meta de juros (aumenta a eficiência e reduz a possibilidade de arbitragem). Além disso, o efeito total sobre as variáveis macroeconômicas é menor do que nos períodos em que o BC não era transparente, ou seja, aumentou o poder do BC em ancorar as expectativas dos agentes econômicos.

Chortareas et al. (2002) também se mostram favoráveis à transparência do $\mathrm{BC}$. O destaque refere-se à transparência relativa às publicações das previsões de inflação, uma vez que a inflação é mais baixa em países que publicam tais informações. Gürkaynak et al. (2005) mostram que os juros futuros são afetados por notícias relativas à meta de inflação e à meta da taxa básica de juros da economia. Neste caso, os autores supracitados reforçam que as informações sobre a política monetária afetam variáveis de longo prazo e, não apenas, variáveis de curto prazo.

O trabalho de Fry et al. (2000) dá destaque à transparência do BC como uma ferramenta que possibilita o BC ser discricionário em um ambiente de regras. Dos 94 países estudados pelo autor, em 1990, apenas 57\% deles adotavam metas explícitas. Em 1998 este número subiu para 97\% ilustrando a tendência de utilização de uma âncora nominal para guiar as expectativas do público. Além disso, a maioria destes países faz análises forward-looking e publicam previsões em forma de gráficos, números ou palavras. Destarte, quase $25 \%$ destes países publicam discussões regulares sobre erros de previsões. Segundo o autor sobredito, os dirigentes destes BCs destacam a transparência como o terceiro atributo mais importante na condução da política monetária.

Os trabalhos teóricos sobre transparência do BC também mostram a sua importância na condução da política monetária. Muitos destes trabalhos estudam os impactos da publicação da meta de inflação, das explicações sobre as decisões de política monetária e das informações sobre o futuro da economia.

Svensson (1999) utiliza um modelo em que o BC se compromete a minimizar sua função de perda e constrói resultados teóricos sobre a influência do grau de transparência do BC na efetividade da política monetária. O autor supracitado defende a importância da transparência sobre a accountability e sobre a credibilidade 
do BC. De acordo com esse modelo, a transparência explicita a meta de emprego (que até então era informação privada do BC) e impossibilita que o BC haja com oportunismo para conter choques idiossincráticos. Esta contingência conduz o BC a ter uma postura mais responsável com relação ao governo, ao público e ao legislativo. Assim, em regimes de metas de inflação implícitas, Svensson (2001) defende a publicação do erro de controle, uma vez que esta publicação deixa explícita a preferência do BC (ex post). Nesse caso, a meta de inflação pode ser obtida por meio de um resíduo, isto é, levando-se em consideração a inflação efetiva e o erro de controle. Em suma, a publicação do erro revela, para o público, as preferências do BC.

Jensen (2000) enfatiza um outro efeito decorrente do anúncio da meta de inflação, isto é, o aumento na sensibilidade da credibilidade do BC às suas ações. Neste caso, o anúncio atua como um mecanismo de comprometimento da autoridade monetária. O autor sobredito alerta que uma maior transparência só é recomendável quando existe informação privada. Caso contrário, o BC incorrerá em custos desnecessários de revelação (custos operacionais e custos de flexibilidade), uma vez que ele se auto-restringirá no processo de reação a choques adversos.

Morris \& Shin (2000) também defendem que a publicação das informações do BC é um fator determinante para o controle das expectativas de inflação. Os autores sobreditos alertam para o fato de que estas expectativas têm uma alta sensibilidade à transparência do BC e, portanto, discussões equivocadas sobre erros passados produzem ruídos que causam incertezas para os agentes econômicos. Assim, os efeitos benéficos da publicação da meta de inflação e das explicações do $\mathrm{BC}$ têm efeito contrário se as informações não tiverem qualidade.

Alguns autores defendem a publicação das metas de inflação e seu cumprimento estrito como política de construção da reputação e da credibilidade do BC. Athey et al. (2001), Herrendorf (1998), Brunilla \& Lahdenperä (1995) destacam que a política ótima do BC é cumprir a meta de inflação. Além disso, Svensson (2001) afirma que tal cumprimento é a principal ferramenta para influenciar as expectativas de inflação. O autor enfatiza que, neste caso, as ações do BC são desprezíveis para a construção da credibilidade do BC.

A importância do desenho institucional e dos modelos de delegação de política monetária é destacada por Eijffinger \& Geraats (2002). Estes autores utilizam modelos similares ao modelo de Lohman (1992) para estudar o efeito da transparência do BC na economia. Geraats (2002) afirma que os benefícios da transparência só se concretizam no caso de o BC ter independência operacional, caso contrário, pressões políticas para a expansão do produto distorcem as ações do BC. Eijffinger \& Hoeberichts (2000) destacam o trade-off entre accountability (construída por meio da transparência do BC) e estabilização. Neste caso, a transparência total reduz as expectativas de inflação e, no entanto, diminui a flexibilidade para estabilizar choques de oferta.

Walsh (2003) elimina o trade-off entre estabilização e flexibilidade ao introduzir no contrato de incentivo uma parcela que pune o BC no caso de a meta 
de inflação ser diferente da inflação efetiva. De acordo com esta interpretação, o maior peso possível deve ser dado ao cumprimento da meta de inflação, uma vez que isto fará com que as expectativas de inflação convirjam para a meta.

Bernanke (2004), Walsh (2003), e Woodford (2005), destacam a importância das publicações de previsões do BC, uma vez que as decisões dos agentes econômicos dependem das taxas de juros futuros da economia. Blinder (2004) também dá ênfase à importância das regras de previsão, em detrimento de regras simples de feedback, uma vez que estas possuem informações restritas sobre o estado futuro da economia. Conforme destaca Bernanke (2004), a qualidade destas informações forward-looking é um pré-requisito para que a transparência do $\mathrm{BC}$ tenha o efeito desejado. Segundo Winkler (2000) esta qualidade, denominada de claridade, é determinante para que o BC construa o conhecimento comum (common knowledge) e faça com que as expectativas de inflação convirjam para a meta. Blinder et al. (2008) destacam a importância da qualidade da informação dos bancos centrais e da habilidade para definir o grau ótimo de transparência.

Vale ressaltar que alguns autores como Geraats (2002) e Walsh (2003) enfatizam a multi-dimensionalidade da transparência do BC. O fato de cada dimensão da transparência ter um efeito diferente nos resultados da política monetária justifica um tratamento diferenciado para cada um deles. Geraats (2002) faz esta diferenciação subdividindo transparência em: transparência política, transparência econômica, transparência de procedimento, transparência da política monetária e transparência operacional.

A autora supracitada define transparência política como a capacidade de o BC revelar os objetivos da política monetária e criar arranjos institucionais que justifiquem as ações dos gestores. Metas para inflação, independência do BC e contratos formais são alguns dos exemplos deste tipo de transparência.

Um outro tipo é a transparência econômica, que diz respeito à definição (clara) sobre qual modelo econômico está pautada a estratégia de política das autoridades monetárias. Além disso, é enfatizada a publicação sistemática de dados econômicos e de previsões sobre choques de oferta.

A transparência de procedimento especifica a responsabilidade de deliberação e as estratégias da política monetária. A transparência da política, que considera as tendências da política monetária, comunica as decisões correntes e indica as ações futuras do BC.

Uma última forma de transparência é a transparência operacional, que trata da implementação das ações da política monetária. Neste caso, são consideradas as discussões sobre erros de controle e distúrbios de transmissão.

Walsh (2003) se limita a destacar as dimensões política, econômica e das decisões de política monetária. Nesse caso, é dada ênfase à importância das diferentes dimensões da transparência do $\mathrm{BC}$ e à utilização das regras forward-looking para o $\mathrm{BC}$ ancorar as expectativas do público à sua meta de inflação. Desta forma, a maioria dos trabalhos teóricos e empíricos defende que a transparência do BC tem efeitos benéficos sobre as principais variáveis macroeconômicas. Em parti- 
cular, sobre as expectativas de inflação e sobre as taxas de juros futuros. Neste contexto, metas explícitas têm a propriedade de revelar as preferências do BC e contratos de incentivo reforçam a convergência da inflação para a sua meta.

Os modelos híbridos, que combinam regras com discrição, utilizam a transparência do BC para explicar como as ações de curto prazo estão relacionadas com os objetivos de longo prazo (controle da inflação e de suas expectativas). Ademais, estes trabalhos destacam que a comunicação do BC é um fator determinante para a efetividade da política monetária.

\section{O Impacto dos Anúncios e das Publicações do BCB na Curva de Juros}

O modelo de âncora cambial introduziu o regime de metas explícitas no Brasil. Isto ocorreu em meados da década de 1990, com a introdução do Plano Real, que criou uma meta explícita para a taxa de câmbio (monitorada de forma contínua pelos agentes econômicos). Neste caso, o mercado testava, de forma instantânea, se o BC estava cumprindo a meta para a taxa de câmbio. Além disso, passaram a ser realizadas reuniões do Comitê de Política Monetária (COPOM) em que eram discutidas ações de política monetária, as quais eram publicadas em ata.

Apesar da observação acima, o governo do presidente Fernando Henrique Cardoso foi marcado por certo grau de opacidade (entre 1994 e 1999). O BCB preenchia apenas as exigências obtidas na lei 4595, as quais tinham um caráter muito abrangente. A lei de número 4595, de 31/12/1964, define múltiplos objetivos a serem alcançados pelo Conselho Monetário Nacional, dentre eles, o combate a surtos inflacionários ou deflacionários, a recessões e a desequilíbrios conjunturais. Este tipo de informação causa dúvidas sobre a prioridade da política monetária, problema similar àquele que define a função da política monetária na economia norte-americana.

O incremento na transparência do BC na condução da política monetária brasileira está, intimamente, relacionado com a adoção do regime de metas para inflação em junho de 1999. Este modelo de gestão da política monetária não se restringiu em publicar uma meta de inflação. O BCB passou a publicar um relatório trimestral de inflação e uma ata que explica as decisões sobre o principal instrumento de política monetária, isto é, a taxa de juros Selic.

Com a adoção do regime de metas de inflação o presidente da República baixou o decreto número 3088, de 21/06/1999, que exige explicações do BCB de como é definida a meta de inflação e a banda ótima (quantificação). Além disso, ele dá autonomia para o BCB na fixação da meta de instrumento (taxa Selic), que deverá ser utilizada para fazer com que a meta final (de inflação) seja cumprida. Este decreto define uma hierarquia de prioridades e torna obrigatória a divulgação de um relatório (até o último dia do trimestre), que explique o desempenho do regime de metas de inflação, o Relatório de Inflação (RI). Destarte, consta no decreto a exigência quanto à discussão de políticas passadas e seus resultados, assim como a publicação de previsões do BCB. Caso a meta de inflação não seja cumprida, o presidente do BCB terá que explicar as causas do insucesso para o Ministro da 
Fazenda (em carta aberta). Um forte aliado do decreto 3088 é a circular número 3010, de 17/10/2000, que dá limites quanto à periodicidade da publicação das atas do COPOM. Neste caso, o BCB deverá publicar as atas seis dias úteis depois da reunião do comitê.

\subsection{Evidências empíricas}

O objetivo desta seção é fazer uma análise multivariada dos efeitos da transparência do $\mathrm{BCB}$, utilizando como variável dependente a variação da taxa de juros futuros DI com vencimento de 3 meses. É importante ressaltar que as alterações na meta da taxa Selic não são capazes de alterar as principais decisões dos agentes econômicos no curto prazo. Entretanto, conforme destacado por Bernanke (2004), tais alterações são capazes de modificar as taxas de juros futuros. Logo, a escolha desta variável dependente tem como objetivo mostrar o impacto da transparência do $\mathrm{BCB}$ na estrutura a termo da taxa de juros e na duration destas taxas. Esta escolha indica se as publicações e os anúncios do BCB afetam a formação dos preços no mercado futuro. Além disso, as variáveis explicativas do modelo são proxies da transparência do BCB e seus coeficientes medem a reação da variável dependente às informações publicadas.

Os dados utilizados na análise das taxas de juros futuros são obtidos no sítio da Bolsa de Mercadoria e Futuros (BM\&F) e correspondem à taxa média diária dos contratos negociados na BM\&F, calculada pela Central de Custódia e de Liquidação Financeira de Títulos (Cetip), e expressa em taxa efetiva anual (base 252 dias úteis). Os dados relativos à meta da taxa Selic têm como fonte o sítio do $\mathrm{BCB}$ e representam a decisão do COPOM sobre o instrumento de política monetária. Vale ressaltar que todas as informações utilizadas na estimação do modelo econométrico são relativas ao período entre 26/7/2002 e 14/12/2005.

Muller \& Zelmer (1999), Haldane (1997), Siklos (2000), Gürkaynak et al. (2005) fazem análises empíricas utilizando MQO e encontram que a transparência do BC é importante na formação das expectativas dos agentes econômicos. A utilização de uma análise multivariada tem como fundamento os resultados empíricos apresentados na literatura (vide seção anterior) e dá a magnitude da influência da transparência do BC nas variáveis macroeconômicas. Vale ressaltar que a literatura sobre transparência não tem uma análise que incorpore os efeitos dos relatórios de inflação e das atas do COPOM no mercado financeiro brasileiro.

A principal diferença entre os modelos estudados pela literatura recente sobre transparência do $\mathrm{BC}$ e o modelo desta seção é a quantidade de proxies utilizadas para representar esta variável. Os autores supracitados utilizam apenas a mudança da meta de juros como medida da transparência do BC e fazem a estimação por MQO. De forma diferente, utiliza-se o método GARCH para fazer as estimações relativas às variações das taxas de juros futuros de três meses, uma vez que variáveis do mercado financeiro apresentam variâncias que se aglomeram ao longo do tempo. ${ }^{1}$ Além das alterações na meta Selic (variável "DDECISAO”),

\footnotetext{
${ }^{1}$ Pindyck \& Rubinfeld (2004) destacam este fenômeno e sugerem uma estimação de variáveis do
} 
são consideradas variáveis dummies construídas a partir de dados publicados nos RI e das informações publicadas nas atas do COPOM. A vantagem da utilização destas séries reside no fato de que elas captam a qualidade da informação publicada pelo BCB e, portanto, mostram a importância da linguagem do BCB na formação das expectativas dos agentes econômicos brasileiros.

Três variáveis dummies referentes às previsões de inflação são utilizadas na estimação, cujos valores são zero nos dias em que o evento não acontece (publicações dos relatórios de inflação) e 1 nos dias em que ele acontece. Neste caso, o relatório de inflação do BCB pode publicar previsões da inflação do período corrente maiores que a meta de inflação do ano em questão. Caso isto aconteça a variável dummy é representada pela PREVMETA1, se esta diferença for negativa utiliza-se a variável dummy PREVMETA2, e se a diferença for nula a variável analisada é a dummy PREVMETA3. Estas variáveis representam a transparência econômica, uma vez que elas são utilizadas como regra de previsão do BCB para aumentar o common knowledge.

Além das variáveis explicativas mencionadas são consideradas outras variáveis dummies, relacionadas às publicações das atas do COPOM. De forma similar ao caso anterior, os valores são zero nos dias em que o evento não acontece (publicações das atas do COPOM) e 1 nos dias em que ele acontece. Estas variáveis captam os efeitos das informações contidas nas atas do COPOM sobre a duration da taxa de juros e são ferramentas importantes para o BCB guiar as expectativas dos agentes econômicos. Vale ressaltar que o COPOM publica, em suas atas, o placar relativo à decisão da meta Selic e, desta forma, é necessário analisar decisões unânimes (ATAUNÂNIME), não unânimes (ATANÃOUNÂNIME) e atas sem placar (ATASEMPLACAR), de forma separada.

Outra variável explicativa utilizada no modelo econométrico é a variação do risco país (DRISCOPAIS). Vale ressaltar que a medida de risco-país considerada é a série de spread do título público soberano - Bônus Global República 40 emitido pelo governo brasileiro, sendo esse spread calculado como pontos-base em relação ao título do Tesouro dos EUA de mesma maturidade. Por se tratar de uma emissão governamental e amplamente negociada nas bolsas de valores internacionais, a diferença de retorno entre o Bônus Global 40 e o título americano de mesma maturidade, este último assumido pelo mercado como livre de risco, expõem o prêmio exigido pelos investidores para cobrir os eventuais riscos de deslocarem seus recursos para um mercado como o Brasil.

mercado financeiro por meio da técnica GARCH. 
O modelo a ser estimado tem como variável dependente a variação da taxa de juros futuros DI com vencimento de 3 meses (DJURT3). Portanto, as variáveis explicativas são descritas por: DDecisAo, PREVMETA1, PREVMETA2, PREVMETA3, ATAUNANIME, ATANAOUNANIME, ATASEMPLACAR, e DRISCOPAIS.

Dado que estimações com variáveis não-estacionárias podem causar regressões espúrias, o primeiro procedimento a ser adotado é analisar se as séries estudadas são estacionárias. A tabela 1 mostra as estatísticas (e os valores críticos) dos testes de raízes unitárias Dickey-Fuller (ADF) e Phillips Pherron (PP). Além disso, foi utilizado o critério de Schwarz para definir o número de defasagens e, portanto, para definir a estrutura do modelo.

A variação das taxas de juros futuros DI com vencimento de 3 meses não exibe raiz unitária, para o período estudado, uma vez que seus valores críticos são menores do que as estatísticas dos dois testes (ADF e PP). A figura 1 ilustra o comportamento da variável dependente e mostra que ela varia em torno de uma média, apesar de estar sujeita aos fenômenos auto-realizadores (característica comum às variáveis do mercado financeiro e representada pela aglomeração das variâncias). Além disso, as séries das variáveis DDecisAo e DRISCOPAIS não possuem raiz unitária no período entre 26/7/2002 e 14/12/2005 (vide tabela 1). Portanto, tais variáveis explicativas podem ser utilizadas na estimação, assim como a variável dependente.

Tabela 1

Teste de Raiz Unitária (ADF e PP) período 26/7/2002-14/12/2005

\begin{tabular}{|c|c|c|c|c|c|c|}
\hline & Séries & Def & Teste & $\begin{array}{c}\text { Valor } \\
\text { crítico } 1 \%\end{array}$ & $\begin{array}{c}\text { Valor } \\
\text { crítico } 5 \%\end{array}$ & $\begin{array}{c}\text { Valor } \\
\text { crítico } 10 \%\end{array}$ \\
\hline \multirow{3}{*}{ ADF } & DJURT3 & 1 & $-29,3123$ & $-2,5675$ & $-1,9411$ & $-1,6164$ \\
\hline & DDECISAO & 19 & $-29,6984$ & -25.675 & $-1,9411$ & $-1,6164$ \\
\hline & DRISCOPAIS & 0 & $-8,5963$ & $-2,5676$ & $-1,9411$ & $-1,6164$ \\
\hline \multirow{3}{*}{ PP } & DJURT3 & 1 & $-29,313$ & $-2,5675$ & $-1,9411$ & $-1,6164$ \\
\hline & DDECISAO & 0 & $-29,6984$ & $-2,5675$ & $-1,9411$ & $-1,6164$ \\
\hline & DRISCOPAIS & 21 & $-7,2818$ & $-2,5676$ & $-1,9412$ & $-1,6165$ \\
\hline
\end{tabular}

Nota: no teste Dickey-Fuller Aumentado (ADF) o critério de informação de Schwarz foi utilizado para definir a defasagem final. No teste Phillips-Perron (PP), a defasagem é o lag truncation escolhido para o núcleo de Barllet. Os testes foram feitos sem a utilização de constante e de tendência. 


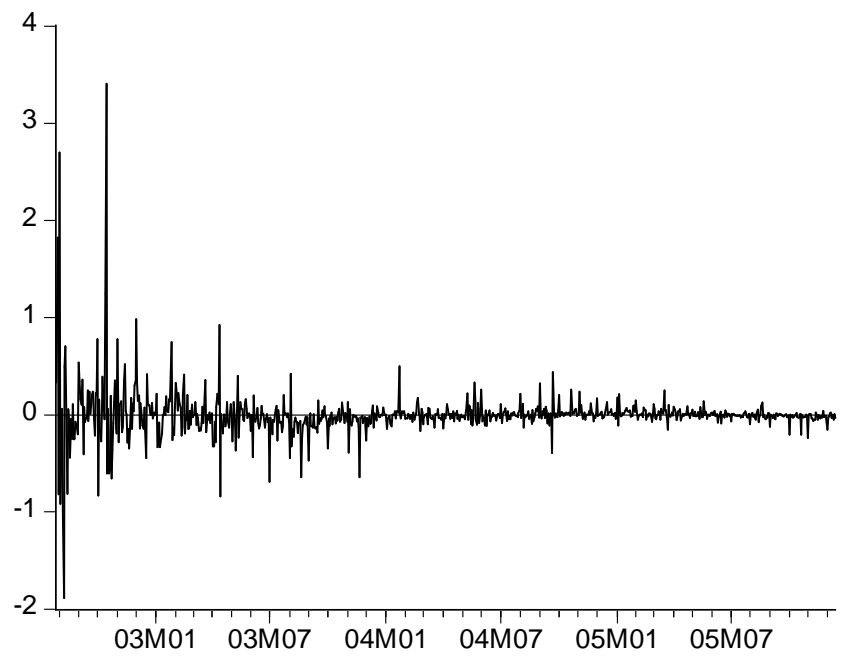

Figura 1

Efeito "manada" na variação da taxa de juros futuros de 3 meses

Definidas as variáveis explicativas e a variável dependente, fez-se uma estimação via MQO, que mostra uma aglomeração das variâncias dos resíduos da regressão ao longo do tempo (vide figura 2). Este é um comportamento típico de variáveis relacionadas ao mercado financeiro e é intitulado por Pindyck \& Rubinfeld (2004) de efeito "manada" (neste caso, ativos financeiros são afetados por fenômenos auto-realizadores). Para que este comportamento seja bem representado, o primeiro passo é incluir uma variável $\mathrm{ARCH}$, cuja variância do resíduo é afetada por erros passados relativos a estes resíduos. Além disso, inclui-se um componente $\mathrm{GARCH}$, que representa a dependência da variância do resíduo à sua variância do período anterior. 


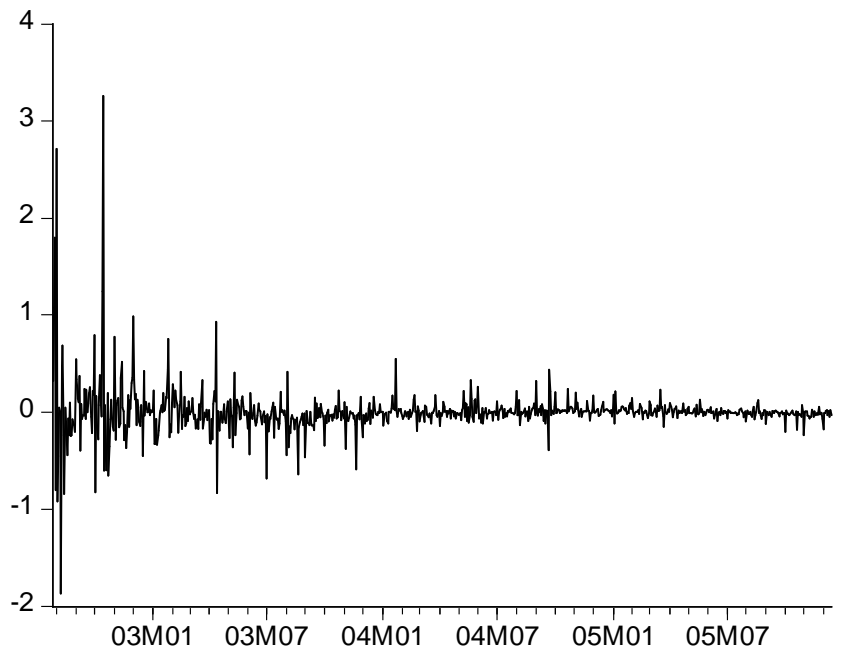

Figura 2

Efeito "manada" nos resíduos da regressão

O pacote econométrico Eviews 5 estima os coeficientes desta regressão, a partir da maximização de uma função de máxima verossimilhança, e tem a vantagem de determinar se a relação entre a variável dependente e as variáveis explicativas é linear ou não. No caso de haver linearidade, não é necessário fazer iterações sucessivas para achar o valor dos parâmetros. Entretanto, se a relação for não-linear faz-se uma aproximação de Taylor em torno dos valores iniciais dos parâmetros. A partir daí, é feita uma nova estimação de MQO, que resulta em novos valores dos coeficientes das variáveis explicativas.

De forma recursiva, é feita uma nova expansão de Taylor ao redor destes valores e, portanto, repete-se o procedimento anterior, isto é, estima-se o modelo linearizado por meio de MQO. Estas iterações acontecem até que a diferença entre os valores dos coeficientes das estimações seja muito pequena.

No período entre 01/06/2004 e 13/03/2006 a incerteza com relação às preferências do BCB era reduzida, uma vez que as ações da nova diretoria do BCB sinalizavam para o mercado o seu compromisso com o regime de metas de inflação. Neste contexto de transparência total, todas as dimensões da transparência afetaram o DJURT3 (vide tabela 2). Esta variável é influenciada, de forma significativa, por informações relativas ao futuro da economia e, como destaca Bernanke (2004), são as regras de previsão que afetam as taxas de juros futuros (variável em que os agentes econômicos baseiam suas decisões). 
Tabela 2

Estimação GARCH - DJURT3 (26/7/2002 14/12/2005)

\begin{tabular}{lcc}
\hline \multicolumn{1}{c}{ Regressores } & Coeficiente & Estatística $z$ \\
\hline $\mathrm{C}$ & $-0,0027$ & $-0,8085$ \\
DDECISAO & 0,0328 & $3,0234^{* * *}$ \\
DRISCOPAIS & $5,27 \mathrm{E}-05$ & 1,3139 \\
PREVMETA1 & 0,0315 & $2,2889 * *$ \\
PREVMETA2 & 0,0025 & 0,0007 \\
PREVMETA3 & $-1,3732$ & $-0,7669$ \\
ATAUNANIME & 0,0427 & $6,1095^{* * *}$ \\
ATANAOUNANIME & $-0,1987$ & $-13,6662^{* * *}$ \\
ATASEMPLACAR & 0,0027 & $2,72 \mathrm{E}-10$ \\
\hline Equação da Variância & & \\
$\mathrm{C}$ & 0,0012 & $10,6021 * * *$ \\
RESID $(-1)^{2}$ & 0,456 & $12,5189 * * *$ \\
GARCH(-1) & 0,6406 & $36,3894 * * *$ \\
\hline $\mathrm{R}^{2}$ ajustado 0,0291 & Estatística F & 2,3724 \\
$\mathrm{~N}$. OBS. 884 & Estat. Durbin-Watson & 2,0725 \\
\hline
\end{tabular}

Nota: variável dependente - Variação da taxa de juros futuros de 3 meses. Coeficientes são significativos ao nível de $1(* * *), 5(* *)$, e $10(*)$ por cento, respectivamente.

O efeito da PREVMETA1 na variável dependente mostra que se o BCB publicar um relatório de inflação, em que a previsão de inflação para o ano corrente é maior que a sua meta, a variação dos juros futuros de 3 meses é positiva (coeficiente de 0,0315$){ }^{2}$ Portanto, os agentes econômicos acreditam que, no futuro próximo, o BCB vai aumentar a taxa básica de juros da economia com o objetivo de atingir sua meta de inflação do ano calendário. Vale ressaltar que os efeitos das publicações dos RIs não possuem significância estatística quando a diferença entre a previsão da inflação e a meta de inflação do ano corrente for negativa ou nula (vide PREVMETA2 e PREVMETA3). Além disso, a variável "DDECISAO" tem um efeito positivo sobre os juros futuros de 3 meses (coeficiente de 0,0328 ), o que corrobora os resultados da literatura relativos aos efeitos da taxa Selic na estrutura a termo da taxa de juros.

A significância estatística das atas unânimes e não unânimes do COPOM denota que ambas afetam a duration das taxas de juros, uma vez que elas provocam variações com prazos maiores que aquelas com prazo de um dia (taxa Selic). Por outro lado, as atas sem publicação de placar possuem coeficientes não significativos, o que mostra a ineficácia deste tipo de informação sobre as expectativas dos agentes econômicos. Ademais, os resultados apresentados na tabela 2 indicam que os agentes econômicos reagem mais às informações das atas não unânimes (coeficiente de -0,1987) do que às informações das atas unânimes (coeficiente igual a 0,0427).

\footnotetext{
${ }^{2}$ Embora o $\mathrm{R}^{2}$ ajustado apresente um valor muito baixo, é importante destacar que não se pretendeu explicar a variação da taxa de juros futuros DI com vencimento de 3 meses, mas avaliar a importância de determinadas variáveis na sua explicação.
} 
É importante ressaltar que o sinal negativo do coeficiente das atas não unânimes em relação à variação dos juros futuros de 3 meses, se justifica pelo fato de que, em sua maioria, são atas que explicam a redução da taxa Selic. Além disso, dado que existe um ajustamento negativo nos dias de ata se comparado aos dias sem ata (variável omitida), mostra uma mudança de direção no comportamento dos juros futuros por parte agentes econômicos.

A alta magnitude da reação da variável dependente às atas não unânimes (coeficiente de -0,1987) está relacionada à qualidade das informações, mais especificamente, à mudança na linguagem do $\mathrm{BCB}$ (tal como ocorrido no Federal Reserve em 2004). Conforme identificado por de Mendonça \& Simão (2008), há um aumento no conteúdo informativo das atas no período entre janeiro de 2004 e outubro de 2005. No caso das atas não unânimes, que explicam a queda da taxa Selic, houve uma melhora no conteúdo informativo, pois os votos de discordância da decisão passaram a ser explicados. Esta surpresa, relativa à transparência das preferências dos membros do COPOM, foi determinante para que houvesse uma mudança na reação dos juros futuros. Ademais, a maior sensibilidade dos juros futuros supracitados à publicação de atas sem unanimidade pode ser devido ao fato de que depois de uma ata não unânime sempre existe uma ata unânime, que segue a opinião dos dissidentes da ata anterior (vide tabela 3 ).

A última variável explicativa a ser analisada é a variação do risco país (DRISCOPAIS) e os resultados mostram que o seu coeficiente não é significativo e apresenta um valor muito baixo. Uma possível explicação para esse resultado se deve ao fato de que ao longo do período analisado a economia brasileira melhorou os seus fundamentos econômicos o que, por sua vez, amorteceu os efeitos provenientes de turbulências internacionais. 
Tabela 3

Decisões do COPOM (22/7/2002-22/12/2005)

\begin{tabular}{|c|c|c|c|}
\hline Data & Decisão & Data & Decisão \\
\hline $22 / 7 / 2002$ & não unânime & $25 / 3 / 2004$ & unânime \\
\hline $20 / 8 / 2002$ & unânime & $22 / 4 / 2004$ & unânime \\
\hline $20 / 9 / 2002$ & unânime & $27 / 5 / 2004$ & não unânime \\
\hline $30 / 9 / 2002$ & unânime & $24 / 6 / 2004$ & unânime \\
\hline $21 / 10 / 2002$ & unânime & $29 / 7 / 2004$ & unânime \\
\hline $30 / 10 / 2002$ & unânime & $26 / 8 / 2004$ & unânime \\
\hline $20 / 11 / 2002$ & unânime & $23 / 9 / 2004$ & não unânime \\
\hline $26 / 12 / 2002$ & unânime & $28 / 10 / 2004$ & unânime \\
\hline $20 / 1 / 2003$ & unânime & $25 / 11 / 2004$ & unânime \\
\hline $20 / 2 / 2003$ & unânime & $23 / 12 / 2004$ & unânime \\
\hline $20 / 3 / 2003$ & unânime & $27 / 1 / 2005$ & unânime \\
\hline $21 / 4 / 2003$ & sem placar & $24 / 2 / 2005$ & unânime \\
\hline $20 / 5 / 2003$ & unânime & $24 / 3 / 2005$ & unânime \\
\hline $27 / 6 / 2003$ & unânime & $28 / 4 / 2005$ & unânime \\
\hline $31 / 7 / 2003$ & unânime & $27 / 5 / 2005$ & unânime \\
\hline $28 / 8 / 2003$ & unânime & $23 / 6 / 2005$ & unânime \\
\hline $24 / 9 / 2003$ & unânime & $28 / 7 / 2005$ & unânime \\
\hline $30 / 10 / 2003$ & unânime & $25 / 8 / 2005$ & unânime \\
\hline $27 / 11 / 2003$ & não unânime & $22 / 9 / 2005$ & unânime \\
\hline $24 / 12 / 2003$ & unânime & $27 / 10 / 2005$ & unânime \\
\hline $16 / 1 / 2004$ & não unânime & $1 / 12 / 2005$ & unânime \\
\hline $25 / 2 / 2004$ & unânime & $22 / 12 / 2005$ & não unânime \\
\hline
\end{tabular}

Fonte: $\mathrm{BCB}$

É importante ressaltar que no modelo estimado a constante não tem significância estatística e não há auto-correlação serial dos resíduos (Durbin-Watson 2,0725). Ademais, a significância estatística das variáveis explicativas da equação da variância (RESID(-1)^2 e GARCH(-1)) reforçam a hipótese de heterocedasticidade condicional nos resíduos da regressão, o que, por conseguinte, confirma o comportamento observado na figura 2 , e portanto mostra que o $\operatorname{GARCH}(1,1)$ é a melhor forma de modelar a variância dos resíduos.

Conclui-se que as decisões sobre a meta Selic afetam a variação das taxas de juros futuros DI com vencimento de 3 meses, uma vez que esta variável cresce com o aumento da meta Selic. Além disso, as atas têm o poder de influenciar os juros futuros de 3 meses. As informações relativas à diferença entre a previsão de inflação do BCB (nos RIs) e a meta de inflação também se relacionam, de forma positiva, com a DJURT3, o que mostra a importância desta informação na curva de juros da economia brasileira.

Por fim, o coeficiente da variável DRISCOPAIS mostra que a formação das expectativas do mercado brasileiro está mais relacionada às notícias e às informações publicadas pelo BCB do que pelas informações relativas ao risco país. Portanto, com a adoção do regime de metas para inflação o BCB aumentou seu poder de 
influência na economia e reduziu a vulnerabilidade das expectativas dos agentes econômicos às noticias da economia internacional. Vale ressaltar que, no caso do $\mathrm{BCB}$, a adoção do regime de metas de inflação não significa apenas a publicação de uma meta final, mas também, de uma tecnologia de comprometimento que depende da transparência (anúncio das decisões sobre a Selic, relatórios de inflação e atas) e da accountability do BCB (decreto 3088).

\section{Conclusão}

Os resultados encontrados pelos diversos autores, tanto nos modelos teóricos quanto nos trabalhos empíricos, convergem para um ponto comum, a transparência do BC é benéfica para a economia. Primeiro porque reduz a assimetria de informações entre o público e o BC, e segundo porque aumenta a accountability do BC. Este resultado é similar àquele encontrado na seção 3 deste artigo, em que as estimativas de máxima verossimilhança mostram a importância das diferentes dimensões da transparência do BCB na curva de juros. Neste caso, a variação da taxa de juros futuros de 3 meses é influenciado pelas informações publicadas nos relatórios de inflação, nas decisões do COPOM e no boletim FOCUS. Quanto maior a diferença entre a previsão da inflação do BCB e a meta de inflação do ano corrente, maior é a variação da taxa de juros futuros de 3 meses. Isto acontece, uma vez que são necessários reajustes nos juros correntes para que a inflação atinja sua meta e como existe uma correlação positiva entre juros futuros e juros correntes, o coeficiente é positivo.

As atas do COPOM também influenciam a taxa de juros futuros de 3 meses. Portanto, são determinantes na formação das expectativas dos agentes econômicos quanto à duration da taxa de juros. Vale ressaltar que as mudanças positivas na meta Selic, relativa às decisões de política monetária, causam mudanças positivas (significativas) na variação da taxa de juros futuros de 3 meses. Isto mostra que a informação sobre a meta Selic tem um efeito importante sobre as expectativas das taxas de juros futuros. Por fim, observa-se que a variável relacionada à economia internacional, a variação do risco país, não afeta a variação dos juros futuros de 3 meses.

\section{Referências}

Athey, Susan, Atkeson, Andrew, \& Kehoe, Patrick J. 2001. On the Optimality of Transparent Monetary Policy. Federal Reserve Bank of Minneapolis, Working Paper 613.

Bernanke, Ben S. 2004. The Logic of Monetary Policy. Before the National Economists Club, Washington, D.C., Federal Reserve Board, December 2.

Blinder, Alan. 2004. Central Banking in Theory and Practice. Cambridge: MIT Press. 
Blinder, Alan, Ehrmann, Michael, Fratzscher, Marcel, Hann, Jakob de, \& Jansen, David-Jan. 2008. Central Bank Communication and Monetary Policy: A Survey of Theory and Evidence. Journal of Economic Literature, 46, 910-945.

Brunilla, Anne, \& Lahdenperä, Harri. 1995. Inflation-Targets: Principal Issues and Practical Implementation. In: Haldane, A. G. (ed), Targeting Inflation. Bank of England, 119-134.

Chada, Jagjit S., \& Nolan, Chadha. 2001. Inflation Targeting, Transparency and Interest Rate Volatility: Ditching 'monetary Mystique' in the UK. Journal of Macroeconomics, 23, 349-66.

Chortareas, Georgios, Stavage, David, \& Sterne, Gabriel. 2002. Does It Pay To Be Transparent? International Evidence from Central Bank Forecasts. Review, Federal Reserve Bank of St. Louis, 84, 99-118.

Clare, Andrew, \& Courtenay, Roger. 2001. What Can We Learn About Monetary Policy Transparency from Financial Market Data? Bundesbank Discussion Paper 06/01.

Eijffinger, Sylvester C., \& Geraats, Petra M. 2002. How Transparent are Central Banks? CEPR Discussion Paper 3188.

Eijffinger, Sylvester C., \& Hoeberichts, Marco M. 2000. Central Bank Accountability and Transparency: Theory and some Evidence. Bundesbank Discussion Paper 06/00.

Fry, Maxwell, Julius, Deanne, Mahadeva, Lavan, Roger, Sandra, \& Sterne, Gabriel. 2000. Key Issues in the Choice of Monetary Policy Framework. Pages 1-216 of: Mahadeva, L., \& Gabriel, S. (eds), Monetary Policy Frameworks in a Global Context. London: Routledge.

Geraats, Petra M. 2002. Central Bank Transparency. Economic Journal, 112, 532-565.

Gürkaynak, Refet, Sack, Brian, \& Swanson, Eric. 2005. The Sensitivity of LongTerm Interest Rates to Economic News: Evidence and Implications for Macroecoeconomic Models. American Economic Review, 95, 425-436.

Haldane, Andrew. 1997. Designing Inflation Targets. In: Monetary Policy and Inflation Targeting. Sydney: Reserve Bank of Australia. Proceedings of a conference held by the Reserve Bank of Australia, 21-22.

Herrendorf, Berthold. 1998. Inflation Targeting as a Way of Precommitment. $O x$ ford Economic Papers, 50, 431-448.

Jensen, Henrik E. 2000. Optimal Degrees of Transparency in European Union Countries. Working Paper, University of Copenhagen. 
Lohman, Susanne. 1992. Optimal Commitment in Monetary Policy: Credibility versus Flexibility. American Economic Review, 82, 273-286.

Mendonça, Helder F. de, \& Simão, José Filho. 2008. Macroeconomic Effects of Central Bank Transparency: The Case of Brazil. Cato Journal, 28, 117-137.

Morris, Stephen, \& Shin, Hyun S. 2000. Welfare Effects of Public Information. Bundesbank Discussion Paper 07/00.

Muller, Phillippe, \& Zelmer, Mark. 1999. Greater Transparency in Monetary Policy: Impact on Financial Markets. Bank of Canada Technical Report 86.

Pindyck, Robert S., \& Rubinfeld, Daniel L. 2004. Econometria: Modelos e Previsões. Editora Campus.

Siklos, Pierre L. 2000. Monetary Policy Transparency, Public Commentary, and Market Perceptions About Monetary Policy in Canada. Discussion Paper Series 1: Economic Studies, 08, Deutsche Bundesbank, Research Centre.

Svensson, Lars O. 1999. Monetary Policy Issues for the Eurosystem. NBER Working Paper 7177, June.

Svensson, Lars O. 2001. What is Wrong with Taylor Rules? Using Judgment in Monetary Policy Through Targeting Rules. mimeo, Princeton University.

Walsh, Carl. 2003. Accountability, Transparency, and Inflation Targeting. Journal of Money, Credit, and Banking, 35, 829-849.

Winkler, Bernhard. 2000. Which Kind of Transparency? On the Need for Clarity in Monetary Policy-Making. ECB Working Paper N. 26, European Central Bank.

Woodford, Michael. 2005. Central Bank Communication and Policy Effectiveness. NBER Working Papers 11898, National Bureau of Economic Research. 